This is a self-archived version of an original article. This version may differ from the original in pagination and typographic details.

Author(s): Aittola, Helena; Ursin, Jani

Title: Finnish adult students' perspectives on short-cycle study programmes : motives and evaluations

Year: 2019

Version: Accepted version (Final draft)

Copyright: @ 2018 HERDSA

Rights: In Copyright

Rights url: http://rightsstatements.org/page/lnC/1.0/?language=en

Please cite the original version:

Aittola, H., \& Ursin, J. (2019). Finnish adult students' perspectives on short-cycle study programmes : motives and evaluations. Higher Education Research and Development, 38(2), 205-218. https://doi.org/10.1080/07294360.2018.1515182 


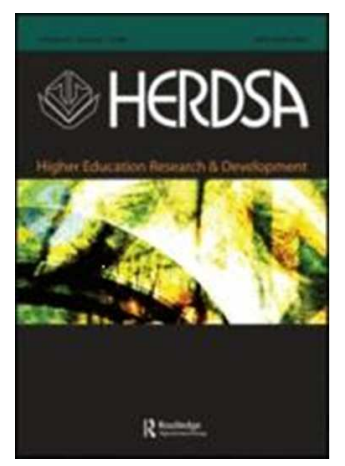

\section{Finnish Adult Students' Perspectives on Short-Cycle Study Programmes: Motives and Evaluations}

\begin{tabular}{|r|l|}
\hline Journal: & Higher Education Research \& Development \\
\hline Manuscript ID & CHER-2017-0496.R1 \\
\hline Manuscript Type: & Article \\
\hline Keywords: & $\begin{array}{l}\text { Higher education policy, Motivation, Qualitative research, Student } \\
\text { experience, Adult education }\end{array}$ \\
\hline \multicolumn{2}{|l}{} \\
\hline
\end{tabular}

\section{SCHOLARONE" \\ Manuscripts}




\title{
Finnish Adult Students' Perspectives on Short-Cycle Study Programmes: Motives and Evaluations
}

\author{
We investigated how students in Finland perceive short-cycle higher education \\ programmes. In line with the European trend, Finland has piloted short-cycle \\ study programmes in order to attract adult students into higher education. We \\ found that the students were mainly satisfied with their studies, and that their \\ orientations to studies and learning were extrinsic in nature. The strengths of the \\ programme were perceived as related to the flexibility of the studies, the variety \\ of teaching methods, and the extensive contents of the studies. The main \\ challenges were associated with difficulties in using ICT within the studies, and \\ issues with time management. The study sheds light on how more open higher \\ education structures and study processes can promote participation in higher \\ education among adult students.
}

Keywords: adult education; higher education policy; motivation; qualitative research; student experience

\section{Introduction}

European higher education systems are in a state of flux. The structures, processes, and contents of education are being challenged by trends that are visible all over the world. One of the most active debates concerns efforts to bring in new groups of students to higher education (Reed, King and Whiteford 2015; Wilkins and Burke 2015).

The framework and criteria for admission to higher education are often determined by national legislation and policy decisions. Recently, however, supranational policy recommendations, such as those stemming from the European Union, have increasingly influenced European higher education policies (Kirsch and Beernaert 2011), with national higher education systems being expected to modify their admission criteria and degree structures accordingly. One example of this trend can be seen in how some EU countries have introduced what are termed short-cycle higher 
education (SCHE) qualifications, in response to the educational aspirations of a wider student population. According to Kirsch and Beernaert (2011, 10-16), in the European context, SCHE can be seen as the missing link between secondary and higher education. Non-traditional and adult students in particular are increasingly participating in SCHE, combining work with education and training. SCHE education aims to meet the demands of the labour market, and to enhance the employability and employment rate of students. In addition, students can use the credits earned in SCHE to progress to degree courses.

In spite of the unification processes, there is more diversity than uniformity in Europe regarding the ways in which SCHE is implemented (cf. Cremonini 2010; Kirsch and Beernaert 2011; Slantcheva-Durst 2010). Finland has adopted an experimental model in which SCHE leads to a diploma rather a degree. Since this is a new offering in the Finnish higher education system, it is important to know the motives of students for participation, their satisfaction with the studies, and the strengths and challenges in the programme. Hence, this study fills in a clear gap, providing new information on students' experiences of SCHE programmes in Finland.

As summarised by Gegenfurtner et al. (2009), the motives of students to participate in training can be internal (involving an internalised desire to participate) and/or external (involving regulation by external rewards). There are also many challenges to participation; these can relate to institutions (which can influence, for example, time management and the organisation of assignments) or to individuals (involving a lack of time and/or motivation) (Bowl 2001; Whitelock et al. 2015). The present study sought to bring new insights to this issue by investigating how adult students in Finland perceive short-cycle higher education programmes. It was 
anticipated that the study would provide empirical findings regarding students' experiences of short-cycle study programmes.

\section{Motives and Challenges in Short-Cycle Study Programmes}

\section{Motives Stemming from the Social Context}

In their investigation of theoretical models of participation in adult education, Boeren, Nicaise, and Baert (2010) found that decisions related to participation depend on three elements: the individual, the institution, and the wider social context. Boeren et al. (ibid.) noted that the main focus in participation models is often on the individual.

Williams (1997) argued that the sets of social and personal factors interact, and impact on individual decision-making in a variety of ways, depending on individual backgrounds and circumstances. For instance, whilst the institutional barriers to inclusive higher education are combatted by a range of governmental and institutional policies, it is unlikely that the demand-side, particularly new demand, could be stimulated without addressing the specific situations of individuals. This indeed was the case in Finland when short-cycle higher education programmes were introduced: the programmes were justified as providing completely open access to higher education, and as offering opportunities to persons with an interest in academic knowledge, or a desire to update and upgrade their skills (cf. Osborne 2016). In fact, the purpose of short-cycle higher education programmes in Finland is not primarily to facilitate access to mainstream higher education qualifications. Nonetheless, evidence from Ireland, for example, suggests that extramural provision can act as an informal 'first step' for many adult students, either by allowing them to 'test the waters' in higher education, or by increasing their interest in such a progression (Inglis and Murphy 1999). 
Initiatives for wider participation in Finnish higher education fall mainly under the responsibility of the Open University. Recently, the role of the Open University as a provider of adult education in Finland (similar to its role in other Nordic countries) has changed; it has become more oriented to working life and to professional education (Antikainen 2016; Haltia et al. 2014), paving the way for the adoption of vocationally oriented short-cycle programmes.

\section{Individual Motives for Participation}

People's life histories are affected not only by their social contexts but also by their personal and psychological characteristics, within which motivation plays an important role. Many studies indicate that it is more reasonable to use the concept of motivational orientations in referring to the reasons why an individual participates in a training programme. Typically, adult learners' motivational orientations are multidimensional and varied.

In seeking to demonstrate the variety of motivational factors, Houle (1993) has presented a widely applied conceptual framework encompassing the individual's orientations towards learning. The framework comprises goal-oriented, activityoriented, and learning-oriented adult learners. Goal-oriented adults participate in an educational programme because of their need for education, or because of a personal interest. An activity-oriented adult chooses an educational programme primarily for the sake of social experiences with other adults. Adults who are learning-oriented perceive continued learning as a duty, and believe that studying will enhance their lives (Houle 1993). In broad alignment with this, Francois's (2014) study indicated that the main reasons for non-traditional adult students' attendance in higher education degree programmes were professional advancement, cognitive interest, and educational preparation. 
Another way to approach the issue is to examine the economic circumstances and necessities which are often used as justifications for adult students' entry to higher education (e.g. Bowl 2001). The rise in adult unemployment, and workers' need to reskill themselves for future employment, have set demands for the higher education system to widen access for 'non-traditional' students, and for underrepresented student groups. Having conducted a wide empirical study concerning participation in adult learning in OECD countries, Pont (2004) found that adults' learning needs are associated with the labour market and economic development. These prompt them to seek further education, with a view to upgrading their professional competences. This has also been the case in Finland, where mediocre economic prospects have forced a rethink on how to organise higher education so that it would better meet the needs of individuals and the labour market.

According to Davies et al. (2002), the motives to participate in adult training for adult students include an improvement in financial circumstances, perceptions of labour market opportunities, and career aspirations. Carré (1998; see also de Oliveira Pires 2009) expands Houle's typology, summarising individuals' motives and orientations towards learning and training activities as involving intrinsic and extrinsic motives. In line with Gegenfurtner et al. (2009), we here define internal motives as an internalised desire to participate in learning experiences when the desire is initiated and governed by the self. External motives, for their part, refer to a desire to participate when the desire is regulated by external rewards or sanctions.

Carré (1998, as adapted by de Oliveira Pires 2009) summarises three intrinsic motives for participation in adult learning. First of all, there is the epistemic motive, in which learning and knowledge are a source of satisfaction and pleasure (the motivation is linked to its own content: to learn, acquire knowledge, skills, attitudes, etc.). 
Secondly, the socio-emotional motive stresses that adults are interested in learning activities because they want to establish social contacts. Thirdly, when governed by the hedonic motive, adults' participation in learning activities is related to the pleasure of participation, which is linked to the conditions of the training environment itself. According to Carré (1998, as adapted by de Oliveira Pires 2009), there are in fact a number of extrinsic motives for participation in adult learning. The economic motive refers to reasons for participation in learning activities that are explicitly material (such as to get promotion, or a job). The prescriptive motive concerns explicit external pressure (obligation) or subtle pressure (social pressure) to participate. The derivative motive involves the avoidance of unpleasant situations, as when adults participate in learning/training activities to escape from suffering or boredom at work. The professional operative motive highlights the notion that the reason for learning is related to developing competences, knowledge, and skills. In the personal operative motive, adults learn to acquire competences, knowledge, and skills that are understood as necessary for activities beyond the job and working life. The identity motive is related to acquiring competences, knowledge, skills, or symbolic recognition by which one can transform or preserve adult identity characteristics. When guided by the vocational motive, learning is orientated by a logic of professional guidance, career management, or getting a job.

\section{Challenges to Participation}

Challenges in participation can be broadly divided into those stemming from institutions and those attributable to individuals. Bowl (2001), suggests that institutional barriers, often relate to learning the rules of academia - time management and the organisation of assignments - and to 'comprehending the mysteries of academic culture and conventions' (Bowl 2001, 157). However, according to research literature, the main 
reasons for inequities in participation relate to individual challenges. Lack of time is the most typical reason to preventing full participation or successful completion of the studies. This relates closely to difficulties in reconciling studies, family life, and professional activity (de Oliveira Pires 2009). Tight timetables and a heavy workload mean that there are not the possibilities to give as much time to studies as desired (Bowl 2001; Whitelock et al. 2015).

The second important individual challenge is a lack of motivation. Many adults see adult learning as unnecessary, and hence not worth engaging in at all. Silvennoinen and Lindberg (2015) have noted that in Finland, as in many other European countries, it is those persons with the highest educational attainment levels who feel a desire to participate, and who actually do participate more keenly in further education and training. This demonstrates the close complementary relationship between initial education and adult learning.

On a global level, financial constraints form the third important barrier (Bowl 2001). In the Finnish system this is a lesser obstacle, since the adult education provided by the Open Universities is priced fairly modestly. On the other hand, many Finns consider free education to be a basic right; hence even modest fees can be viewed as a deterrent to participation in adult education.

\section{The Aims and Setting of This Study}

In 2013 the Finnish Ministry of Education and Culture proposed a national pilot project on the Diploma of Higher Education as a means of widening entry to higher education for a range of adult students (Ministry of Education and Culture 2013). These Diploma programmes were intended to provide training by which adult students could complement their existing skills and knowledge, or develop new competences in specific fields of study at tertiary level. One tertiary education institution received 
permission and resources from the Ministry to pilot and implement four short-cycle study programmes (covering Agricultural Entrepreneur Business Competence, Gerontological Rehabilitation, HR and Financial Specialists, and Purchasing Professionals).

The actual programmes were organised by the Open University, operating under the University of Applied Sciences (UAS) system. They were intended to comply with the principles applying to Open University studies; thus, the applicants could enrol in the studies irrespective of their age, educational background, or work experience. In line with these principles, the students were charged a tuition fee of $€ 10$ per ECTS credit. (Author 1 2016; Author 2 2016.)

The courses for the short-cycle study programmes were selected from the institution's degree programmes, the aim being that the enrolling students would follow the same course contents as degree students. However, the course modules were drawn from various fields of study, and from basic and advanced vocational degree programmes. The scope of the Diploma studies was set at 60 ECTS credits $(1$ ECTS $=$ 27 study hours, 1 year of studies $=60$ ECTS credits) for each programme. It was estimated that the 60 ECTS credits would take about a year and a half to complete on a part-time basis. These programmes did not in themselves lead to a degree, although the students would get a certificate on completing their studies. However, the studies could be later incorporated into a bachelor's degree, since Open University courses can be credited towards a degree at a UAS. (Author 1 2016; Author 2 2016.)

The main objective of the present study was to explore how the programmes were perceived by the participating students themselves, in terms of providing them with new knowledge, and with qualifications for advancing in working life and following further studies. The specific research questions were as follows: 
1. What were the motives of the students for participating in the short-cycle study programmes?

2. How were the short-cycle study programmes organised in seeking to satisfy the training needs of adult students?

3. What strengths and challenges did the students perceive in their studies?

\section{Data and Methods}

Design

The target population of the study comprised students $(n=85)$ enrolled in the autumn of 2014 in the four short-cycle study programmes that had been set up (aiming towards the Diploma of Higher Education). The characteristics of the participants, as discovered in the present study, are described in Table 1.

--- Insert Table 1 here ---

The data for our study was collected by interviews with students, and by an online survey completed by the students. The interview data from students were collected during the spring of 2015 . The interviews were with 17 students, representing $23 \%$ of the entire student group $(n=74)$ who were continuing their studies towards the Diploma. Most of them were female and over 40 years old. Their educational background was fairly high, although about one fifth of the Diploma students (20.5\%) would not have fulfilled the basic admission requirements for higher education BA degree studies. In connection with this, it should be noted that students who complete general upper secondary education would normally have the requirements allowing them to begin studies at a university, at a university of applied sciences, or within 
vocational training, in line with the general upper secondary education syllabus (cf. Haltia et al. 2014; Silvennoinen and Lindberg 2015).

The invitations for the interviews were sent via student email lists, and the students could participate in interviews on a voluntary basis. The interviewees were selected to represent each of the study programmes. At the time of the interviews, which took place in the spring of 2015, the students had already completed approximately twothirds of their studies. The online survey was delivered via the institution's email list (covering all actively studying students) after the interviews, and 44 of the actively studying students responded (response rate $=59.5 \%$ ).

\section{Measures and analyses}

The aim of the interviews was to gather students' preliminary perceptions of the Diploma studies, and also to provide insights for the design of the online survey. The interviews were semi-structured, and focused on the following main themes: motivation to apply for short-cycle programme studies, satisfaction with ongoing studies (especially regarding study contents and methods), foreseeable occupational relevance of the studies, and general perceptions on the pilot programmes. The main themes were identical in each interview, but the questions in the interviews were adapted to the interviewees' answers in the conversations. Three of the interviews were carried out in group situations, and seven of them were conducted individually.

In designing the online survey, the researchers took into consideration national and international research literature (see the Introduction) and findings from the interview data. The survey consisted of 25 questions, and included questions on the students' background, plus their assessments of the short-cycle programme studies. It had structured items (on a scale of 1 to 5) concerning (i) motives to apply for short- 
cycle programme studies ( 8 items), (ii) the contents of studies, plus the quality of the studies and the study conditions (25 items), (iii) the study methods ( 7 items), and (iv) the occupational relevance of the studies (6 items). In addition, the students could give open-ended responses to questions concerning the strengths and challenges pertaining to the pilot programmes.

The interviews and open-ended responses in the survey constituted the qualitative data of the study. The students' responses were classified qualitatively into main categories, outlined on the basis of earlier research. Inter-rater reliability assessments were not conducted, since all the steps in the coding were carefully documented so that they could be checked by another researcher if necessary. This has been considered to be a satisfactory procedure in guaranteeing the consistency of the analysis, bearing in mind that the use of inter-rater reliability measures in studies like ours is debatable (see e.g. Amstrong et al. 1997). The online survey yielded mainly quantitative data, and it was analysed by descriptive statistical methods, such as frequency distributions and cross tabulations. Note that because of the small number of participants in the programmes, it would have been pointless to make statistical comparisons between background variables (such as study programmes, gender, age, educational degree, or work experience).

The findings from the interview data and from the online survey are here viewed as complementary. Translated and anonymised citations from interviews and online survey data are used to illustrate students' views on the aspects under study.

\section{Findings}

\section{Students' Motives to Participate in Short-Cycle Study Programmes}

The findings from the survey and from the interviews provided a consistent account of 
the motives. The motives of the participants for engaging in the programmes varied, but were mainly extrinsic. For the most part they related to new challenges faced in work duties and situations, a desire to change one's occupation or field of work, the aspiration to continue to a bachelor's degree, and the need to update skills and knowledge (Table 2).

--- Insert Table 2 here ---

The respondents described their motives more precisely in their interviews. Motives originating from new challenges in their duties or work situations were described in the following way:

This fits perfectly with my present job. Up to now, so many new things have come up which can be applied to my work. In my case it's hard to see how there could be better training, or a better study programme in general. There are already plenty of one- or two-day courses available. After a few of these courses I can say that they just scratch the surface in comparison with this programme. (Interview: Purchasing professional)

For some participants, the studies could provide an opportunity to change their occupation or field of work. One respondent illustrated this aim as follows:

\begin{abstract}
My work tasks changed a year ago, since the beginning of the year, more or less accidentally. I've never previously been in any kind of HR administration posts for a longer term. I don't have the actual training for this area, from my previous training, so it reinforces my own competences. (Interview: HR and Financial Specialist)
\end{abstract}

Some respondents reported that they aimed at degree studies at a university of applied sciences (UAS). The Diploma programme could provide them with appropriate 
1

2

3

4

5

6

7

8

9

basics for degree studies in the study field aimed at. One respondent described this aim as follows:

I would have done it already earlier if it was possible. As I didn't get admitted to the educational institute. I'll complete this and then to try get in to do degree studies, and gain the right to study in the spring. Because I intend to go on for the degree, I find this as a fairly flexible way to do it. (Interview: Gerontological Rehabilitation)

Most of the students who had had a long work career wanted to update their skills and knowledge and supplement their prior studies, because of prospective changes in their duties. This reflects a general trend, in which the changing world of work requires people to improve and deepen their expertise, irrespective of the specific field of the work. The short-cycle study programmes were seen as ways to enhance the students' professional competences. One respondent described this as follows:

At the University of Helsinki I studied forestry. Then I set up a firm a couple of years ago and I noticed this chance to do more studying online, and to do more of that agricultural side. The aim would be to work in both the forestry and the agriculture sector in the future. In addition, there was a generational change at our home farm, and that calls for agricultural education. It came as a good opportunity to cover both at the same time. (Interview: Agricultural Entrepreneur Business Competence)

One of the main premises at the outset of the study programme was that it would provide new skills for working life. Most of the students were studying as well as working. The students said that as the learning assignments had been firmly connected to the practices of their work organisations, the studies had brought added value both at individual and organisational level:

I've really been able to link these to my own organisation. It has been terrific that I have been able to consider those things through my own work and job. It's been 
beneficial, just for my daily work, and then also to be given a chance to bring new ideas and viewpoints to the workplace. (HR and Financial Specialist)

According to students' views in the survey, concerning expectations for future positions in the labour market, the studies were not expected to bring any radical improvement (Table 3). The responses to the question concerning employment after the studies showed that students would mostly retain their status at the workplace. However, some of them believed that after completing the studies, they would be assigned more challenging duties.

\section{--- Insert Table 3 here ---}

\section{Satisfaction with the Studies}

The aim of the pilot project was to organise the short-cycle study programmes in such a way as to satisfy the training needs of adult students with particular needs. In the survey the students were asked to give an overall rating (on a scale of 1 to 5) to their studies. The mean value was $3.9(n=39)$, suggesting that the respondents were fairly satisfied with their studies. The respondents also gave very favourable evaluations of their experiences, and of the contents and implementation of the studies (Table 4).

According to the responses, the studies provided entirely new knowledge in the fields concerned. The studies were also considered useful and practical with regard to the students' various occupational needs. From the students' standpoint, the theoretical orientation and the practice-based implementation of the studies were well-balanced. The basic pedagogical procedures, and the flexible online and heterogeneous training models, were perceived as equally appropriate. One student from the HR and Financial Specialist programme summed up his preference for online studies:

I particularly liked the fact that there is not even a single day of contact teaching. One can do it all online and during or outside working hours. (Interview) 
There were also some indisputable advantages connected to the varied nature of the studies, as described by one student from the Purchasing Professional programme:

\begin{abstract}
These contact teaching days are extremely important. If this sort of thing was done merely as an online course, you wouldn't learn even half of it. The discussion and inclusion of different viewpoints is extremely important. There, people have already put aside all notions of being a star performer, so you don't need feel ashamed when you open your mouth. In a way, there's no question of people being unwilling to state their opinion or their own view, or to speak up and give comments. (Interview)
\end{abstract}

\title{
--- Insert Table 4 here ---
}

Overall, the students' accounts in the survey confirmed the positive evaluations given for the programme. The responses exemplified high satisfaction with study experiences (Table 4). The differing educational backgrounds of the students, originating from varying work histories and sectors, were generally seen as an enrichment. The students could easily share knowledge and communicate with each other, as described by one of the Gerontological Rehabilitation students:

\begin{abstract}
We are a tremendously active group, that's why these contact teaching days are so wonderful. ... There are people who are changing their occupation, and us longterm professionals from the field of healthcare, and also long-term professionals from the social service sector. Those discussions have been really wonderful and enlightening. (Interview)
\end{abstract}

Naturally, the students also expressed some critical comments on the study practices. The online studies were viewed as not entirely functional, and more personal contacts could have enhanced the students' learning:

For example, having contacts with other students or creating a team spirit is difficult there. Especially when there was no actual familiarisation or group 
construction there at the start. (Interview: Agricultural Entrepreneur Business

Competence)

Nevertheless, the students seemed largely satisfied with the studies, even if there had been some disappointing or frustrating study experiences.

\section{Strengths and Challenges of the Studies}

The students could evaluate the strengths and challenges of their short-cycle study programmes by giving open-ended responses in the survey. The responses were classified into four categories. The best aspects of the studies were related to (i) the teaching and learning methods (see Table 5). The points emphasised under this theme (28 references) included the flexibility of studies, varying teaching methods, contact teaching and seminars, online studies, and possibilities to study alongside one's work.

The students also highlighted (ii) the contents of studies (17 references), which were judged to be sufficiently extensive and wide ranging. According to the students, the studies provided up-to-date knowledge, and the relationship between theory and practice was well-balanced. Finally, they expressed general satisfaction with (iii) the teachers, and (iv) the student groups (13 references each). The teaching was perceived to be of a high quality, and to meet the requirements of the academic level. Above all, the social and emotional support of peers played an important role during the learning process.

On the other hand, the students also saw room for development in the programme. The challenges were classified into two categories. Some of the suggestions were connected to (i) the teaching and learning methods (18 references). For example, there were various problems arising from the fact that initially some students were not adequately prepared in the use of new technologies. The timetables for the learning tasks were also thought to be somewhat ill-suited to students' changing 
work and life situations. Adult students might face difficulties with time-management due to their duties or family responsibilities, as one student indicated:

\begin{abstract}
The harmonisation of studying and family life is not a problem in my opinion, neither is the harmonisation of work and family. When you have three balls in the air, then you just have to manage the problems in that setting. First you finish the working day, and then you spend time with the children. Then, once the children are finally asleep, you look what you can still do today. Your own free time is gone. (Survey: HR and Financial Specialist)
\end{abstract}

Critical comments on (ii) the study contents (17 references) focused merely on some individual courses, and not on the programme as a whole. Some students who had already completed a tertiary degree, and who had been working in a particular field for a long time, indicated that the basic courses had not provided anything new for them. Hence, it was argued that students should have the chance to choose their courses on a more individual basis.

\title{
--- Insert Table 5 here ---
}

\section{Conclusions}

We investigated the perceptions of adult students who were following short cycle programmes. The motives for participation in the programmes varied, but were mainly extrinsic (involving e.g. new challenges faced in the work, or a desire to change one's occupation or field of work) (cf. Francois 2014; Pont 2004; Davies et al. 2002). The participants were satisfied with their studies. In particular, the participants felt that they had learned new things, and that the instruction was of a high quality. The strengths of the programmes related to the flexibility of studies, varying teaching methods, and the extensive content of the studies. The main challenges were associated with difficulties 
in using ICT as part of the studies, and issues connected with time management (cf. Bowl 2001; Whitelock et al. 2015).

The findings overall suggest that the Diploma students could be divided into different categories according to the main objective of their studies. One clearly distinguishable group consisted of those who were supplementing or updating their knowledge and degrees. They indicated that the study programme filled in a gap that was missing from their prior studies. This objective - or using the term of Carré (1998), professional operative motive - has been recognised as the most common study motivation (Haltia \& al. 2014; Pont 2004). The other main categories consisted of students who either aimed at degree studies or wanted to change their occupation or field of work. Thus, they exhibited Carré's (1998) economic motive. The Diploma students could not be classified as 'self-developers' with an eye on personal development per se (Haltia \& al. 2014; Pont 2004); rather, they mainly had an extrinsic orientation to their studies, with learning seen as a means to achieve external goals.

Most of the students indicated that the studies had enhanced their professional skills and knowledge, even if these short-cycle study programmes were not targeted at specific professional groups as in-service-training. The trend towards a stronger working-life orientation within higher education has been detected in other Finnish studies (Haltia \& al. 2014). According to Antikainen (2016), within the Nordic countries, the role of the Open University as a provider of adult education has moved towards broader multidisciplinary professional education. In the wider European context, too, it has been discovered that among adult learners, professional development and upskilling are significant motivations for participating in higher education (Dollhausen et al. 2013). 


\begin{abstract}
Although the decisions of the students to participate in higher education seemed to depend mostly on individual work and life conditions, it was the offering of new multidisciplinary short-cycle study programmes that drew adult students from different backgrounds into the programmes. The students did not actually need a new degree; rather, the programmes provided opportunities for those with an interest in academic knowledge or an interest in updating their skills. The Open University was able to respond rapidly to changing work demands and to the training needs of adult students in specific professional fields. Consequently, individual elements showed a successful interaction with institutional elements and with the wider social context. A similar interaction has been found by Boeren et al. (2010) and by Williams (1997) in their models of participation in adult education.

In the present study, the best aspects of the Diploma programme from the students' standpoint were connected to the structural and didactic dimensions (cf. Osborne 2016). The students appreciated the ways in which the programmes fitted organisationally with their work and life situations (see e.g. Pont 2004; Whitelock et al. 2015). In line with this, the heterogeneity of the online studies was seen as well-suited to the different study programmes. However, it was not possible to design totally individual study programmes, as the Diploma studies were composed of complete modules selected from the institute's degree programmes.

In our study, nearly all the students found it difficult to assess the immediate impact of the Diploma programmes on their position in the labour market (cf. also Haltia et al. 2014). In contrast, international findings underline individuals' motivation to pursue a tertiary degree with a view to higher income levels or a higher position in their profession (Dollhausen et al. 2013). The impact of the present Diploma
\end{abstract}


programme on employment possibilities in Finland was clearly limited, given that the training did not yield any formal qualification beyond the Diploma.

The limitations of our study derive mostly from its country-specific context. In Finland, the theme of widening participation in higher education is not as controversial an issue as in more hierarchical educational systems. It is worth noting that the piloting scheme with its short-cycle higher education programmes was not actually aimed at addressing serious inequality problems in the Finnish higher education sector; rather, it was a reaction to recommendations in the wider European higher education context.

Although our study was restricted to one institution with a relatively small sample of students from four different programmes, the findings were consistent with other Finnish and international studies concerning adult students' study orientations and conditions. The study provided valuable evidence on how more open higher education structures and study processes can promote participation in higher education, among adult students who would benefit from education at this level.

\section{References}

Author 12015.

Author 12016.

Author 22016.

Amstrong, D., A. Gosling, J. Weinman and T. Marteau. 1997. "The Place of Inter-Rater Reliability in Qualitative Research: An Empirical Study”. Sociology 31 (3): 597-606.

Antikainen, A. 2016. “The Nordic Model of Higher Education.” In Routledge Handbook of the Sociology of Higher Education, edited by J. E. Côté and A. Furlong, 234-240. Milton Park: Routledge.

Boeren, E., I. Nicaise and H. Baert. 2010. "Theoretical Models of Participation in Adult Education: The Need for an Integrated Model.” International Journal of

Lifelong Education 29 (1): 45-61. doi:10.1080/02601370903471270. 
Boeren, E., E. J. Holford, I. Nicaise and H. Baert. 2012. "Why Do Adults Learn? Developing a Motivational Typology Across 12 European Countries.” Globalisation, Societies and Education 10 (2): 247-269. doi:10.1080/14767724.2012.678764.

Bowl, M. 2001. "Experiencing the Barriers: Non-Traditional Students Entering Higher Education." Research Papers in Education 16 (2): 141-160. doi:10.1080/02671520110037410.

Carré, P. 1998. “Motifs et dynamique d'engagement en formation.” [In French.] Education Permanente, No 136, 119-131.

Cremonini, L. 2010. Short-Cycle Higher Education: An International Review. Enschede: University of Twente, Cheps. http://www.wissenschaftsmanagementonline.de/sites/www.wissenschaftsmanagementonline.de/files/migrated_wimoarticle/001_CHEPS5ShortCycleHE.pdf

Davies, P., M. Osborne and J. Williams. 2002. For Me or Not for Me? - That is the Question: A Study of Mature Students' Decision Making and Higher Education. Research Report 297. London: Department for Education and Skills.

Dollhausen, K., S. Lattke, F. Sheliga, A. Wolter, A. Spexard, J. Geffers and U. Banscherus. 2013. Developing the Adult Learning Sector: Lot 3: Opening Higher Education to Adults: Contract EAC 2012-0074. Final Report. Brussels: Publications Office of the European Union.

François, E. J. 2014. "Motivational Orientations of Non-Traditional Adult Students to Enroll in a Degree-Seeking Program." New Horizons in Adult Education and Human Resource Development 26 (2): 19-35. doi:10.1002/nha3.20060. http://onlinelibrary.wiley.com/doi/10.1002/nha3.20060/full

Gallacher, J., M. Osborne and G. Postle. 1996. "Increasing and Widening Access to Higher Education: A Comparative Study of Policy and Provision in Scotland and Australia.” International Journal of Lifelong Education 15 (6): 418-437.

Gegenfurtner, A., D. Festner, W. Gallenberger, E. Lehtinen, and H. Gruber. 2009. "Predicting Autonomous and Controlled Motivation to Transfer Training." International Journal of Training and Development 13 (2): 124-138.

Haltia, N., L. Leskinen and E. Rahiala. 2014. “Avoimen korkeakoulun opiskelijamuotokuva 2010-luvulla: Opiskelijoiden taustojen, motiivien ja koettujen hyötyjen tarkastelua." [Summary: A Portray of Open University 
Students in the 2010s: Looking at Students' Backgrounds, Motives and Perceived Benefits; in Finnish.] Aikuiskasvatus 34 (4): 244-258.

Houle, C. O. 1993. The Inquiring Mind. $3^{\text {rd }}$ ed. Norman, OK: University of Oklahoma, Oklahoma Research Center for Continuing Professional and Higher Education. Inglis, T. and M. Murphy. 1999. No Room for Adults? A Study of Mature Students in University College Dublin. Project Report. Dublin: University College Dublin, Social Science Research Centre and the Adult Education Office.

Kirsch, M. and Y. Beernaert. 2011. Short Cycle Higher Education in Europe: Level 5: The Missing Link. Summative report. Brussels: EURASHE. http://www.eurashe.eu/library/modernisingphe/L5_report_SCHE_in_Europe_full_report_Jan2011.pdf

Ministry of Education and Culture. 2013. Monipuoliset ja sujuvat opintopolut: Korkeakoulujen koulutusrakenteiden kehittämistyöryhmän muistio [Versatile and Smooth Study Paths: Higher Education Structural development Group's Memorandum: in Finnish]. Reports of the Ministry of Education and Culture 2013:2. Helsinki: Ministry of Education and Culture. https://julkaisut.valtioneuvosto.fi/bitstream/handle/10024/75305/tr02.pdf?sequen $\underline{\mathrm{ce}}=1$

de Oliveira Pires, A. L. 2009. "Higher Education and Adult Motivation Towards Lifelong Learning: An Empirical Analysis of University Post-Graduates Perspectives.” European Journal of Vocational Training 46 (1): 129-150. http://files.eric.ed.gov/fulltext/EJ864793.pdf

Osborne, M. 2016. “Access to Higher Education.” In Routledge Handbook of the Sociology of Higher Education, edited by J. E. Côté and A. Furlong, 119-130. Milton Park: Routledge.

Pont, B. 2004. "Improving Access to and Participation in Adult Learning in OECD Countries.” European Journal of Education 39 (1): 31-45. http://onlinelibrary.wiley.com/doi/10.1111/j.0141-8211.2004.00165.x/abstract

Reed, R., A. King and G. Whiteford. 2015. "Re-Conceptualising Sustainable Widening Participation: Evaluation, Collaboration and Evolution." Higher Education Research \& Development 34 (2): 383-396. doi:10.1080/07294360.2014.956692.

Rowell, C. 2016. "Working-Class Students in Western Higher Education.” In Researching Higher Education: International Perspectives on Theory, Policy and Practice, edited by J. M. Case and J. Huisman, 97-113. London: Routledge. 
Silvennoinen, H. and M. Lindberg. 2015. “Aikuiskoulutukseen osallistuminen Suomessa." [Summary: Participation in adult education in Finland; in Finnish.] Aikuiskasvatus 35 (4): 266-285.

Slantcheva-Durst, S. 2010. "Chapter 1: Redefining Short-Cycle Higher Education Across Europe: The Challenges of Bologna." Community College Review 38 (2): $111-132$.

Whitelock, D., M. Thorpe and R. Galley. 2015. "Student Workload: A Case Study of its Significance, Evaluation and Management at the Open University.” Distance Education 36 (2): 161-176. doi:10.1080/01587919.2015.1055059.

Wilkins, A. and P. L. Burke. 2015. "Widening Participation in Higher Education: The Role of Professional and Social Class Identities and Commitments." British Journal of Sociology of Education 36 (3): 434-452. doi:10.1080/01425692.2013.829742.

Williams, J., ed. 1997. Negotiating Access to Higher Education: The Discourse of Selectivity and Equity. Buckingham: The Society for Research into Higher Education \& Open University Press. 
Table 1. The characteristics of the students enrolled in short-cycle studies $(n=85)$, by the study programmes followed (Author 1 2015; Author 2 2016)

\begin{tabular}{|l|l|l|l|l|}
\hline & $\begin{array}{l}\text { Agricultural } \\
\text { Entrepreneur } \\
\text { Business } \\
\text { Competence } \\
\mathrm{n}=16\end{array}$ & $\begin{array}{l}\text { Gerontological } \\
\text { Rehabilitation } \\
\mathrm{n}=22\end{array}$ & $\begin{array}{l}\text { HR and } \\
\text { Financial } \\
\text { Specialists } \\
\mathrm{n}=24\end{array}$ & $\begin{array}{l}\text { Purchasing } \\
\text { Professionals } \\
\mathrm{n}=23\end{array}$ \\
\hline $\begin{array}{l}\text { Gender } \\
\text { Female } \\
\text { Male }\end{array}$ & $63 \%$ & $100 \%$ & $79 \%$ & $65 \%$ \\
\hline Age (mean) & $37 \%$ & 43 years & 43 years & $35 \%$ \\
\hline $\begin{array}{l}\text { Education } \\
\text { Vocational upper } \\
\text { secondary } \\
\begin{array}{l}\text { UAS } \\
\text { degree }\end{array}\end{array}$ & $44 \%$ & $61 \%$ & $71 \%$ & $32 \%$ \\
$\begin{array}{l}\text { University } \\
\text { degree }\end{array}$ & $12 \%$ & Bachelor's 29\% & Bachelor's 21\% & Bachelor's 45\% \\
\hline
\end{tabular}


Table 2. Students' motives to participate in the Diploma programmes $(n=43)$ (Survey: Percentage of respondents expressing complete or partial agreement with the statements, scores $4-5$ on a scale from 1 to 5)

Motives for participation (number of respondents $=43$ )

I wanted to strengthen my work-related competence. $\quad 93 \%$

The Diploma training offers complementary education

from a field other than that of my previous studies. $\quad 72 \%$

I intend to use the Diploma studies as a step to

a UAS degree programme

$51 \%$ 
Table 3. Students' responses to statements regarding their labour market prospects and changes in their jobs after the studies

\begin{tabular}{|l|l|}
\hline $\begin{array}{l}\text { Statements concerning labour market } \\
\text { prospects }\end{array}$ & $\begin{array}{l}\text { Statements concerning changes in the job } \\
\text { after the studies } \\
\text { Survey: }(\mathrm{n}=27 \text {; percentage of } \\
\text { respondents expressing complete or } \\
\text { partial agreement, } \\
\text { scores 4-5 on a scale from 1 to 5) }\end{array}$ \\
\hline $\begin{array}{l}\text { I will continue in my present job with the } \\
\text { same tasks, 56\% }\end{array}$ & My work will be more independent, 41\% \\
\hline $\begin{array}{l}\text { My work duties will change, but the } \\
\text { employer will be the same, 10\% }\end{array}$ & $\begin{array}{l}\text { I will get more responsibility at work, } \\
33 \%\end{array}$ \\
\hline & $\begin{array}{l}\text { My job description will be broadened, } \\
33 \%\end{array}$ \\
\hline & $\begin{array}{l}\text { I will get more demanding work tasks, } \\
30 \%\end{array}$ \\
\hline & $\begin{array}{l}\text { The Diploma improves my career } \\
\text { prospects, 70\% }\end{array}$ \\
\hline & My income will increase, 11\% \\
\hline
\end{tabular}


Table 4. Students' experiences and evaluations regarding the contents and implementation of the studies. (Survey: Percentage of respondents expressing complete or partial agreement with the statements, scores $4-5$ on a scale from 1 to 5)

\begin{tabular}{|l|l|}
\hline Satisfaction with the studies $(\mathrm{n}=41)$ & $\begin{array}{l}\text { Overall experience of the programme }(\mathrm{n}= \\
41)\end{array}$ \\
\hline $\begin{array}{l}\text { Online and multiform learning suits me } \\
\text { well, } 88 \%\end{array}$ & $\begin{array}{l}\text { The instruction has been of high quality, } \\
90 \%\end{array}$ \\
\hline I have learned new subject matter, 95\% & $\begin{array}{l}\text { I can recommend the programme for } \\
\text { others in a similar situation, } 90 \%\end{array}$ \\
\hline $\begin{array}{l}\text { The instruction has been practice- } \\
\text { oriented, } 85 \%\end{array}$ & $\begin{array}{l}\text { The programme has met my expectations, } \\
85 \%\end{array}$ \\
\hline $\begin{array}{l}\text { The studies have increased my theoretical } \\
\text { understanding, } 85 \%\end{array}$ & $\begin{array}{l}\text { I have gained support for my studies from } \\
\text { the other participants, 71\% }\end{array}$ \\
\hline $\begin{array}{l}\text { The contents of the study modules have } \\
\text { been useful, 90\% }\end{array}$ & $\begin{array}{l}\text { It is good that there are no requirements } \\
\text { for the participants regarding their } \\
\text { educational background or field, } 66 \%\end{array}$ \\
\hline $\begin{array}{l}\text { I have received sufficient personal } \\
\text { guidance when needed, 76\% }\end{array}$ & \\
\hline
\end{tabular}


Table 5. Students' views on the strengths and challenges of the studies (Survey: openended responses)

\begin{tabular}{|l|l|}
\hline $\begin{array}{l}\text { Strengths of the studies (4 categories) } \\
\text { (number of references) }\end{array}$ & \\
\hline $\begin{array}{l}\text { Teaching and learning methods of the } \\
\text { studies (28) }\end{array}$ & $\begin{array}{l}\text { flexibility of the studies, varying teaching } \\
\text { methods, contact teaching and seminars, } \\
\text { online studies, possibilities to study } \\
\text { alongside work }\end{array}$ \\
\hline Contents of the studies (17) & $\begin{array}{l}\text { Sufficiently extensive and multifaceted, } \\
\text { the studies provide up-to-date knowledge, } \\
\text { a balanced relationship between theory } \\
\text { and practice }\end{array}$ \\
\hline Teachers (13) & $\begin{array}{l}\text { high quality of the teaching, academic } \\
\text { level, teachers as competent professionals, } \\
\text { teachers devoted to their work }\end{array}$ \\
\hline Student groups (13) & $\begin{array}{l}\text { participants' differing educational and } \\
\text { occupational backgrounds enrich the } \\
\text { studies, social and emotional support from } \\
\text { peers }\end{array}$ \\
\hline $\begin{array}{l}\text { Challenges of the studies (two } \\
\text { categories) } \\
\text { (number of references) }\end{array}$ & $\begin{array}{l}\text { problems with IT and time management, } \\
\text { timetables too strict for the learning tasks }\end{array}$ \\
\hline Teaching and learning methods (18) & $\begin{array}{l}\text { unnecessary repetition, need for optional } \\
\text { courses }\end{array}$ \\
\hline Study contents (17) & \\
\hline
\end{tabular}

